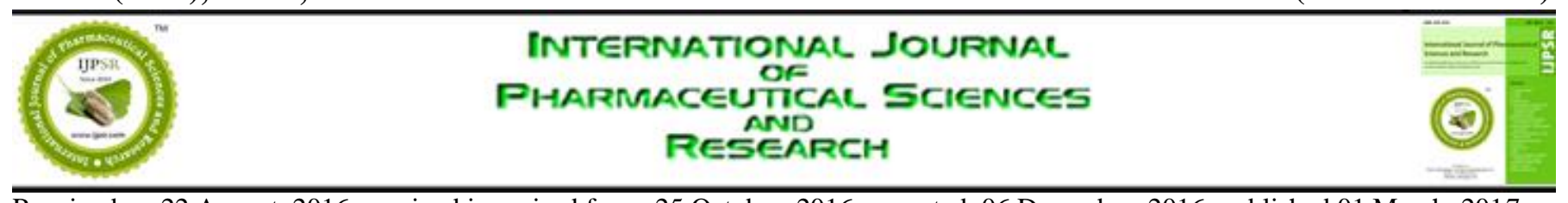

Received on 22 August, 2016; received in revised form, 25 October, 2016; accepted, 06 December, 2016; published 01 March, 2017

\title{
DRUG UTILIZATION PATTERN AMONG GERIATRIC PATIENTS IN A TERTIARY CARE TEACHING HOSPITAL
}

\author{
U. S. Lalwani *, A. Pillai and K. G. Piparva
}

Department of Pharmacology - PDU Medical College, Rajkot, Gujarat, India.

Keywords:

Drug Utilization Study,

Geriatric population, Polypharmacy, Beers criteria, ATC, DDD

\section{Correspondence to Author:}

Dr. Usha S. Lalwani

Sushila Bhavan 5 Premchand Colony, New Jail road, Nr. Army Gate, Jamnagar - 361005, Gujarat, India.

E-mail: ushalalwani89@gmail.com

\begin{abstract}
Objective: To evaluate drug utilization pattern among geriatric patients in outdoor as well as indoor departments of the hospital. Methods: Observational, prospective study was conducted from March 2014 to March 2015 among 600 geriatric patients; demographic details, education, occupation, diagnosis and drug details were recorded. The drugs were categorized by anatomical therapeutic classification and defined daily dose was calculated. The World Health Organization prescribing indicators and potentially inappropriate medicines (PIMs) according to Beers criteria were assessed. Results: The majority of the patients (75\%) were in age group of 65-74 years. Cardiovascular diseases were common among geriatrics. Most commonly prescribed drug was ranitidine $(56 \%)$. Comorbid conditions were present in $34.5 \%$ patients. In OPD and IPD $8.9 \%$ and $4.9 \%$ of drugs were fixed-dose combinations (FDCs) respectively. The mean number of drug formulations per prescriptions was $4.49 \pm 0.7$ in OPD and 7.1 \pm 2.28 in IPD. Polypharmacy was prevalent in $62.5 \%$ of patients. Drugs prescribed by their generic names were $71.3 \%$ in OPD and $62.7 \%$ in IPD and $98 \%$ of were drugs that were included in the National Essential Medicines List (NEML). In OPD $11.5 \%$ and in IPD $7.5 \%$ of drugs prescribed were potentially inappropriate medications (PIMs) according to Beers 2012 criteria.
\end{abstract}

INTRODUCTION: Old age consists of ages nearing or surpassing the average life span of human beings. Old people have limited regenerative abilities and are more prone to diseases, syndromes, and sickness as compared to other adults. Prescribing to older patients is unique challenge because premarketing drug trials often exclude geriatric patients and approved doses may not be appropriate for older adults. ${ }^{1}$ Many medications need to be used with special caution because of age-related changes in pharmacokinetics and pharmacodynamics.

\begin{tabular}{|c|c|}
\hline QUICK RESPONSE CODE & DOI: \\
\hline & $\begin{array}{c}\text { Article can be accessed online on: } \\
\text { www.ijpsr.com }\end{array}$ \\
\hline DOI link: http://dx.doi.org/10.13040/IJPSR.0975-8232.8 (3).1249-54 \\
\hline
\end{tabular}

As the number of medicines taken by geriatric patients and the incidence of ADR is more in this age-group, it becomes increasingly important to study patterns of drug use. The issue of polypharmacy is of particular concern in older people who, compared with younger individuals, tend to have more disease conditions for which therapies are prescribed. Polypharmacy increases the potential for drug-drug interactions and for prescription of potentially inappropriate medications. $^{2}$

Drug utilization research or studies are the powerful exploratory tools to ascertain the role of drugs in the society which refers to the marketing, distribution, prescription and use of drugs with special emphasis on the medical, social and economic consequences. 
So, the principal aim of drug utilization research is to facilitate the rational use of drugs in population. ${ }^{3}$ The anatomical therapeutic chemical classification (ATC) / defined daily dose (DDD) system is a tool for presenting drug utilization research in order to improve quality of drug use and is recommended by the WHO as the international standard for drug utilization studies. $^{3}$

The aim of this descriptive study was to analyse general medication utilization patterns in geriatric patients in a tertiary care teaching hospital.

MATERIALS AND METHODS: This was a record based, observational, prospective study conducted in departments of Medicine, Surgery, Obstetrics and Gynaecology, Orthopaedics, ENT, Ophthalmology, Psychiatry, Skin, Oncology, TB chest and dentistry of tertiary care teaching hospital. The study was conducted from March 2014 to March 2015. The study started after written approval from IEC. Prior permission to conduct study was obtained from Head of Department of each of the above mentioned departments. For recruiting study subjects, one month each was spent in the outdoor and indoor departments of our hospital.

Patients were recruited into the study were given clear explanations about the purpose and nature of the study in a language they understood. Written informed consent was obtained before inclusion in the study. From the case records of the enrolled patients' demographic details, education, occupation, diagnosis, drug details were recorded.

Sample size: Six hundred patients in the geriatric age-group ( $\geq 65$ years), 300 each from the indoor and outdoor departments of PDU medical college and hospital, Rajkot were included in the study. Drug utilization pattern was evaluated by the proportion of patients receiving particular drugs, its pharmacological groups, WHO core indicators, anatomical therapeutic classification (ATC) code, and DDDs/1000 inhabitants/day. ${ }^{4}$ Prescription data presented as DDD/1000 inhabitants/day may provide a rough estimate of the proportion of the study population that may be treated daily with certain drugs. Percentage of potentially inappropriate medicines (PIMs) were analysed according to Beers criteria.
Statistical Analysis: Data were expressed as proportions and mean (95\% confidence interval (CI)). Recorded data were analysed by Microsoft Office Excel 2010 and Graph pad prism 6. Fisher's exact test was applied to see the association between gender and polypharmacy; gender and PIMs; comorbidity and polypharmacy; comorbidity and PIMs; polypharmacy and PIMs. Multivariate logistic regression was applied to predict PIMs from age, gender, polypharmacy and comorbidity.

RESULTS: The demographic data Table 1 shows that the majority of the patients were in the agegroup of $65-74$ years $(75.1 \%)$, followed by agegroup of 75-84 years $(20.6 \%)$; the lowest number of patients $(4.1 \%)$ were in the age-group of $>85$ years. Out of the total 600 patients, $48.6 \%$ were males and $51.3 \%$ were females. The majority of patients, $(42.5 \%)$ had studied only up to primary level followed by illiterate (39.5\%), secondary $(13.6 \%)$ and tertiary $(4.6 \%)$ level.

\begin{tabular}{ccc} 
TABLE 1: "DEMOGRAPHC DATA OF PATIENTS" \\
\hline Parameters & Groups & $\begin{array}{c}\text { No. of patients } \\
(\mathbf{\%}), \mathbf{n}=\mathbf{6 0 0}\end{array}$ \\
\hline Age(years), Mean & $65-74$ & $451(75.1)$ \\
$: 69 \pm 5.3$ years & $75-84$ & $124(20.6)$ \\
& $\geq 85$ & $25(4.1)$ \\
Gender & Male & $292(48.6)$ \\
& Female & $308(51.3)$ \\
Education Status & Illiterate & $237(39.5)$ \\
& Primary & $255(42.5)$ \\
& Secondary & $82(13.6)$ \\
& Tertiary & $26(4.3)$ \\
\hline
\end{tabular}

Majority of the patients were from medicine department $(50.5 \%)$ followed by orthopaedic department (12.8\%) in outdoor department (OPD) as well as indoor department (IPD) (Table 2)

\begin{tabular}{|c|c|c|c|}
\hline \multicolumn{4}{|c|}{$\begin{array}{lcc}\text { TABLE } 2: & \text { "DISTRIBUTION OF } \\
\text { ACCORDING TO DEPARTMENTS" } & \end{array}$} \\
\hline Sr. No. & Department & $\begin{array}{c}\text { No. of } \\
\text { patients in } \\
\text { OPD }\end{array}$ & $\begin{array}{c}\text { No. of } \\
\text { patients in } \\
\text { IPD }\end{array}$ \\
\hline 1 & Medicine & 115 & 128 \\
\hline 2 & ICU & 0 & 60 \\
\hline 3 & Orthopaedic & 51 & 26 \\
\hline 4 & TB \& CHEST & 35 & 13 \\
\hline 5 & Skin & 25 & 0 \\
\hline 6 & Dental & 24 & 0 \\
\hline 7 & Surgery & 20 & 22 \\
\hline 8 & ENT & 9 & 5 \\
\hline 9 & Ophthalmology & 7 & 22 \\
\hline 10 & Gynaecology & 5 & 9 \\
\hline 11 & Psychiatry & 5 & 1 \\
\hline 12 & Cancer & 4 & 14 \\
\hline
\end{tabular}


Diseases related to the cardiovascular system (346; $57.6 \%$ ) were the most common cause for attending the hospital, followed by Diabetes mellitus (73; $12.1 \%)$ and respiratory conditions (41; 6.8\%). Psychiatric diseases $(6 ; 1 \%)$ were the least frequently encountered. Majority of patients (OPD - 68.6\%; IPD - 62.3\%) had single mentioned diagnosis.
Most of the patients were prescribed with drugs acting on GIT $(67 \%)$ among them ranitidine was most common (56\%), followed by analgesics $(53.3 \%)$ and vitamins - minerals $(50.6 \%)$ in OPD. While in IPD most of the patients were prescribed with drugs acting on GIT (72.6\%) among them also ranitidine was most common $(69.3 \%)$, followed by hypolipidemic drugs (50.0\%) and antibiotics $(47.3 \%)$.

TABLE 3:"MOST FREQUENTLY PRESCRIBED DRUGS"

\begin{tabular}{cccc}
\hline Sr. no. & Drugs & No. of patients (OPD) & No. of patients (IPD) \\
\hline 1 & Ranitidine & 168 & 208 \\
2 & Atorvastatin & 51 & 150 \\
3 & Aspirin & 51 & 137 \\
4 & Isosorbide dinitrate & 34 & 114 \\
5 & Diclofenac & 96 & 73 \\
6 & Clopidogrel & 7 & 87 \\
7 & Furosemide & 23 & 69 \\
8 & Enalapril & 57 & 65 \\
9 & Paracetamol & 60 & 45 \\
10 & Calcium & 59 & 35 \\
\hline
\end{tabular}

Table 4 shows WHO prescribing core indicators in OPD and IPD. Average number of drugs per prescription was $4.49 \pm 0.7$ in OPD and $7.24 \pm 2.28$ in IPD. Percentage of drugs prescribed by generic name was $71.3 \%$ and $62.7 \%$ in OPD and IPD respectively. Percentage of patients prescribed with antibiotics was 21.6 in OPD and $47.3 \%$ in IPD. Total patients receiving injections was $21.6 \%$ in OPD and $47.3 \%$ in IPD. Percentage of drugs prescribed from essential drug list were $98.3 \%$ and 98.5\% in OPD and IPD respectively.

TABLE 4: "PRESCRIBING INDICATORS"

\begin{tabular}{ccc} 
Prescribing indicators & OPD & IPD \\
Average number of drugs per prescription & $4.49 \pm 0.7$ & $7.24 \pm 2.28$ \\
Percentage of drugs prescribed by generic name (\%) & 71.3 & 62.7 \\
Percentage of patients prescribed with antibiotics (\%) & 21.6 & 47.3 \\
Total patients receiving injections (\%) & 1.3 & 84.6 \\
Percentage of drugs prescribed from essential drug list (\%) & 98.3 & 98.5 \\
\hline
\end{tabular}

Out of 1349 drugs prescribed among outdoor patients and 2172 drugs prescribed among indoor patients, $8.9 \%$ and $4.9 \%$ of drug formulations were FDCs respectively. In OPD $11.5 \%$ and in IPD $7.5 \%$ drugs prescribed were potentially inappropriate medications (PIMs) according to Beers 2012 criteria. Polypharmacy is common in patients of
IPD $(83.9 \%)$ compared to OPD patients $(41 \%)$. Table 5 shows ten most frequently prescribed drugs in OPD. DDD for ranitidine (A02BA02) 150 mg tablets was 560 DDD/1000 inhabitants/day. Ranitidine, diclofenac sodium and aspirin shows $\mathrm{PDD} / \mathrm{DDD}$ ratio equal to one.

TABLE 5: "TEN MOST FREQUENTLY PRESCRIBED DRUGS AND ATC CODES/DDD, PDD, PDD/DDD OF OPD"

\begin{tabular}{|c|c|c|c|c|c|c|}
\hline Name of drug & $\begin{array}{c}\text { No. of } \\
\text { prescriptions }(\%)\end{array}$ & ATC Code & $\begin{array}{c}\text { WHO DDD } \\
\text { measure }\end{array}$ & $\begin{array}{c}\text { DDDs/1000p } \\
\text { t/day }\end{array}$ & PDD & $\begin{array}{l}\text { PDD/ } \\
\text { DDD }\end{array}$ \\
\hline Ranitidine & $168(56)$ & A02BA02 & $300 \mathrm{mg}$ & 560 & 300 & ;) 1 \\
\hline Diclofenac & $96(32)$ & M01AB05 & $100 \mathrm{mg}$ & 320 & 100 & (;) 1 \\
\hline Calcium & $59(19.6)$ & A12AA03 & $3000 \mathrm{mg}$ & 83.3 & 1271 & 0.42 \\
\hline Enalapril & 57 (19) & C09AA02 & $10 \mathrm{mg}$ & 206.6 & 10.7 & 1.07 \\
\hline
\end{tabular}




\begin{tabular}{|c|c|c|c|c|c|c|}
\hline Folic acid & $49(16.3)$ & В03BВ01 & $0.4 \mathrm{mg}$ & 2041 & 5 & 12.5 \\
\hline Amlodipine & $40(13.3)$ & C08CA01 & $5 \mathrm{mg}$ & 226.6 & 8.5 & 1.7 \\
\hline Isosorbide dinitrate & $34(11.3)$ & C01DA08 & $20 \mathrm{mg}$ & 28.3 & 5 & 0.25 \\
\hline
\end{tabular}

DISCUSSION: Therapeutic practice is expected to be primarily based on evidence provided by premarketing clinical trials, but complementary data from the post-marketing period are also paramount for improving drug therapy. ${ }^{5}$ Drug utilization studies (DUS) are conducted to know the current prescribing trends and to evaluate nature, extent and determinants of use. This will help to determine and employ rational use of drugs among population. ${ }^{3}$ The geriatric population is on the rise worldwide. This population is vulnerable to many diseases and drug-related problems. Limited data are available in general, and in India in particular, on drug utilization in this population. This study was done to understand the pattern of drug use and related issues in geriatric patients.

In our study the percentage of female patients $(51.3 \%)$ was only marginally higher than male patients (48.6\%), with male to female ratio 0.9:1. Similar findings are reported by Jhaveri BN et $\mathrm{al}^{6}$. Most of the patients were educated up to primary level $(42.5 \%)$, similar results were found in the study conducted by Shah RB et al in rural settings. ${ }^{7}$

Majority of the patients were from medicine department $(50.5 \%)$ followed by orthopaedic department (12.8\%) in outdoor department (OPD) as well as indoor department (IPD) (Table II). Similar findings are reported by Kumar T. et al. ${ }^{8}$

Diseases related to the cardiovascular system (346; $57.6 \%$ ) were the most common cause for attending the hospital, followed by Diabetes mellitus (73; $12.1 \%)$ and respiratory conditions $(41 ; 6.8 \%)$. Psychiatric diseases $(6 ; 1 \%)$ were the least frequently encountered. This is in sharp contrast to the findings from western countries, where psychiatric conditions were among the most commonly encountered disease. ${ }^{9}$ Poor awareness regarding psychiatric illness among patients and family members may be responsible for low prevalence of psychiatric conditions in our study. Similar study by Jhaveri BN et al ${ }^{6}$ and Shah RB ${ }^{7}$ et al also showed diseases related to cardiovascular system as the most common cause for attending hospital.
Majority of patients (OPD - 68.6\%; IPD - 62.3\%) had single mentioned diagnosis and least number of patients (OPD - 31.3\%; IPD - 37.6\%) had comorbidity. It may be due to poor history and record of other comorbid diseases. Study by Shah $\mathrm{RB}$ et al showed majority of patients $(78.7 \%)$ had comorbidity. ${ }^{7}$ In presence of comorbidities means that multiple and complex drug therapy is required and thus the chances of ADRs and drug interactions are greater.

Table 3 shows most of the patients were prescribed with drugs acting on GIT (67\%) among them ranitidine was the most common (56\%), followed by analgesics (53.3\%) and vitamins - minerals $(50.6 \%)$ in OPD. It is justifiable to use analgesics for relief of pain and as conservative management of diseases .While in IPD most of the patients were prescribed with drugs acting on GIT (72.6\%) among them also ranitidine was most common $(69.3 \%)$, followed by hypolipidemic drugs $(50.0 \%)$ and antibiotics (47.3\%). It is justifiable to use analgesics for relief of pain and as conservative management of diseases, while use of ranitidine in such a large number of patients is irrational since very few patients complained of gastritis but it may be given to the patients as prophylaxis for the side effects of multiple drugs used at a time. Results of study done by Shah RB et al also showed highest use of group A drugs (alimentary and metabolism) according to ATC classification. ${ }^{7,}{ }^{4}$ It showed irrational use of Ranitidine is common.

The DDD system is a tool for national and international comparison of drug consumption. The defined daily dose is the assumed average maintenance dose per day for a drug used for its main indication in adults. In our study DDD for ranitidine $(150 \mathrm{mg})$ tablets was $560 \mathrm{DDD} / 1000$ inhabitants/day, which means every alternate patient visiting OPD is receiving ranitidine in a DDD indicating very high consumption in our setup. Another drug-utilization study done by Shah $\mathrm{RB}$ et al ${ }^{7}$ also showed higher DDD for ranitidine. The ratio of PDDs and DDDs for the ten most frequently used drugs in OPD was also calculated in our study. 
The DDD is a unit of measurement and does not necessarily agree with the recommended or prescribed daily dose (PDD). In our study PDD/DDD ratio is equal to one for ranitidine, diclofenac sodium and aspirin. When the PDD/DDD ratio is either less than or greater than one, it may indicate either under or over utilization of drugs. In our study the PDD/DDD ratio is much higher in case of folic acid (12.5) and little high in case of amlodipine (1.7) followed by atorvastatin (1.3) and hence they are overused; while this ratio is lower in case of isosorbide dinitrate (0.25), paracetamol (0.27), calcium (0.42) and hence they are underused.

Multivariate logistic regression: was applied to predict potentially inappropriate medicines (PIMs) from age, gender, polypharmacy and comorbidity. In the present study it shows, as comorbidity increases there are chances of increasing PIMs.

Fisher's exact test: significant association was found between comorbidity and polypharmacy ( $\mathrm{p}=$ $<0.0001)$; comorbidity and PIMs $(\mathrm{p}=<0.0001)$ but association was not significant between gender and polypharmacy $(p=0.5)$, gender and PIMs $(p=0.8)$, PIMs and polypharmacy $(\mathrm{p}=0.2)$

Limitations and Future Perspectives: The cost component of the drug therapy as part of DDD could not be computed due to unavailability of relevant data. Besides, the number of patients in the study is also relatively small. As there are only few similar studies in the Indian setting, we believe that our study is innovative in nature and that our findings provide baseline data for comparison with the findings of similar studies in future.

CONCLUSION: Polypharmacy and PIMs prescribing in geriatric patients a global problems. There is a strong and urgent need of developing prescribing guidelines for elderly patients for different conditions. The same must be implemented in all health/medical care setups. Geriatric population needs efficient and safe medical care, which can be provided only by rational prescribing and using medicines for them safely.

ACKNOWLEDGEMENT: Mere words of thanks can never unload the burden of my indebtedness and gratitude to many individuals who in one way or other contributed and extended their valuable support and assistance in planning, conduct and completion of this study.

Words can hardly express my deep sense of gratitude and indebtedness to Dr. Ajita Pillai, Dr. Kiran G. Piparava, Dr. Shailesh Mundhava and Dr.Jigar Modi for their timely attention, constant supervision and assessment of study, practical tips, critical and valuable suggestions throughout the study.

CONFLICT OF INTEREST: I certify that neither I nor any member of this study has a material personal or financial relationship with any offeror, or to a direct competitor of any offeror. I further certify that no other relationship, bias or ethical conflict exists.

\section{REFERENCES:}

1. Cho S, Lau SW, Tandon V, et al. Geriatric drug evaluation: where are we now and where should we be in future? Arch Intern Med 2011; 171:937.

2. Weng MC, Tsai CF, Sheu KL, et al. The impact of number of drugs prescribed on the risk of potentially inappropriate medication among outpatient older adults with chronic diseases. QJM 2013; 106:1009.

3. Introduction to Drug Utilization Research. Oslo: World Health Organization; 2003. Chapter 1, What is drug utilization research and why is it needed? p.8-12.

4. WHO Collaborating Centre for Drug Statistics Methodology, Guidelines for ATC classification and DDD assignment 2010. Oslo, 2009.

5. Thakkar KB, Jain MM, Billa G, Joshi A, Khobragade AA. A Drug Utilization Study of Psychotropic Drugs Prescribed in the Psychiatry Outpatient Department of a Tertiary Care Hospital. J Clin Diagn Res. 2013;7(12):2759-64.

6. Jhaveri BN, Patel TK, Barvaliya MJ, Tripathi CB, Drug utilization pattern and pharmacoeconomic analysis in geriatric medical in patients of a tertiary care hospital of India : Bhavnagar J Pharmacol and Pharmacotherapeutics January-March 2014 Vol 5 Issue.

7. Shah RB, Desai SV, Gajjar BM, Drug utilization pattern among geriatric patients assessed with the anatomical therapeutic chemical classification / defined daily dose system in a rural tertiary care teaching hospital: Karamsad Int J Nutr Pharmacol Neurol Dis 2012;2:258-65

8. Ramesh Kumar T, Shahina S, Shobha JC, Naidu MUR, Usha Rani P, Vijay T. a study on Drug Utilization in Geriatric Population in a tertiary care centre. Hyderabad: J K Science 1999; Vol. I No.3, July-September

9. National institute of health. The number count: Mental disorders in America, 2008. [Last cited on 2009 Nov 22]. Available from: http://www.nimh.nih.gov/health/ publications/the-numbers-count-mental disorders-inamerica/ index.shtml. [Last accessed on 2015 Oct 12].

10. Introduction to Drug Utilization Research. Oslo: World Health Organization; 2003. Chapter 2, Types of drug use information; p.13-9. 
11. Introduction to Drug Utilization Research. Oslo: World Health Organization; 2003. Chapter 6, Drug utilization

metrics and their applications; p.38-41.

How to cite this article:

Lalwani US, Pillai A and Piparva KG: Drug utilization pattern among geriatric patients in a tertiary care teaching hospital. Int J Pharm Sci Res 2017; 8(3): 1249-54.doi: 10.13040/IJPSR.0975-8232.8(3).1249-54.

All @ 2013 are reserved by International Journal of Pharmaceutical Sciences and Research. This Journal licensed under a Creative Commons Attribution-NonCommercial-ShareAlike 3.0 Unported License.

This article can be downloaded to ANDROID OS based mobile. Scan QR Code using Code/Bar Scanner from your mobile. (Scanners are available on Google Playstore) 